See Article page e129.

\section{Commentary: Curiouser and curiouser-The role of exosomes in transplant rejection}

\author{
Brian Bateson, DO, and Victor van Berkel, MD, $\mathrm{PhD}$
}

For many end-stage lung diseases, lung transplantation remains the only available treatment. Over the last 30 years, the use of lung transplantation has grown worldwide, with a slow but consistent improvement in outcomes. ${ }^{1}$ Despite this improvement, the prevalence of chronic rejection and its clinical manifestation bronchiolitis obliterans syndrome (BOS) remain unchanged, affecting $10 \%$ of patients annually or $50 \%$ at 5 years. ${ }^{2}$ Ultimately, graft failure for these patients is based on the development of chronic rejection. There continues to be no effective treatment for BOS, even though and significant research has gone into identifying the pathways for chronic rejection in the hopes of understanding its progression and providing a means to delay its onset.

The easiest-to-understand pathways to transplant rejection center on the recognition of donor antigens via recipient $\mathrm{T}$ cells. This has been classically consider to occur via 2 mechanisms, the first of which is direct recognition of donor leukocytes by the recipient immune system. This pathway is thought to be involved primarily in acute rejection, as the donor lymphocytes are typically present for only a limited time after transplantation. The more chronic pathway involves the recipient antigen-presenting cells (APCs) presenting donor antigens via the recipient's major histocompatibility complex (MHC) molecules-essentially treating the donated lung as an infection to be cleared. ${ }^{3}$ Another mechanism has been described: a "semidirect" pathway in which recipient APCs present intact donor MHC molecules, although the means of transfer of these complex molecules has been a mystery. In this issue of the Journal, Hwang and colleagues ${ }^{4}$ describe how exosomes participate in this pathway via a variety of mechanisms.

\footnotetext{
From the Department of Cardiovascular and Thoracic Surgery, University of Louisville School of Medicine, Louisville, Ky.

Disclosures: The authors reported no conflicts of interest.

The Journal policy requires editors and reviewers to disclose conflicts of interest and to decline handling or reviewing manuscripts for which they may have a conflict of interest. The editors and reviewers of this article have no conflicts of interest.

Received for publication April 17, 2020; revisions received April 17, 2020; accepted for publication April 17, 2020; available ahead of print May 11, 2020.

Address for reprints: Victor van Berkel, MD, PhD, 201 Abraham Flexner Way, Suite 1200, Louisville, KY 40202 (E-mail: victor.vanberkel@1ouisville.edu).

J Thorac Cardiovasc Surg 2021;161:e135-6

$0022-5223 / \$ 36.00$

Copyright (c) 2020 by The American Association for Thoracic Surgery

https://doi.org/10.1016/j.jtcvs.2020.04.121
}

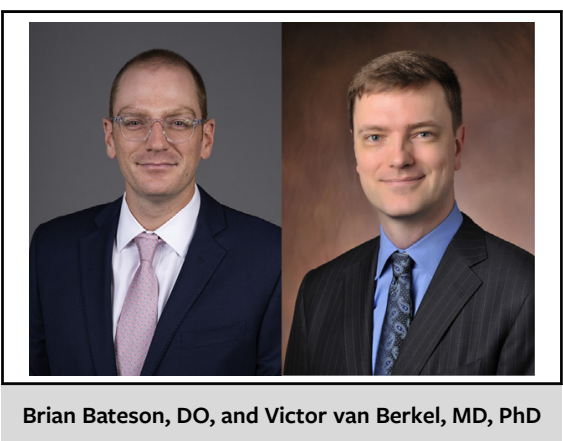

\section{CENTRAL MESSAGE \\ Exosomes play a role in the development of rejection in lung transplantation.}

Their review notes the previously extensively described classic allorecognition pathways that drive rejection following lung transplantation and identify exosomes as a critical component of both innate and adaptive immunity in transplant rejection. ${ }^{5}$ The authors review the available literature for exosome-mediated allorecognition and provide in excellent detail the different mechanisms that have been described. Although exosomes have been used as biomarkers for rejection in animal models for years, they recently have been identified after lung transplantation in clinical studies. ${ }^{6}$ Identifying exosomes as a key component of both innate and adaptive immunity should spur further research into its role in lung transplant rejection. This hopefully will lead to the same improvement in chronic rejection that we have already seen in acute rejection, with comparable improvements in outcomes for lung transplantation as seen in other solid organ transplantations over the last couple of decades.

Exosome-based allorecognition pathways warrant further investigation to gain a better understanding of chronic rejection. The authors have done an excellent job reviewing the current understanding of these pathways and point to the questions that exosomes may be able to answer. This article will hopefully drive further investigation into exosomes and lead to delayed onset of chronic rejection or better management strategies, ultimately leading to a new wonderland of lung transplantation.

\section{References}

1. Chambers DC, Cherikh WS, Goldfarb SB, Rossano JW, Stehlik J. The International Thoracic Organ Transplant Registry of the International Society for Heart and Lung Transplantation: Thirty-fifth adult lung and heart-lung transplant report-2018; Focus theme: multiorgan transplantation. J Heart Lung Transpl. 2018;37:1169-83.

2. Grossman EJ, Shilling RA. Bronchiolitis obliterans in lung transplantation: the good, the bad, and the future. Transl Res. 2009;153:153-65. 
3. Lin CM, Gill RG. Direct and indirect allograft recognition: pathways dictating graft rejection mechanisms. Curr Opin Organ Transpl. 2016;21:40-4.

4. Hwang B, Bryers J, Mulligan MS. Potential role of exosome-based allorecognition pathways involved in lung transplant rejection. J Thorac Cardiovasc Surg. 2021; 161:e129-34.
5. Robbins PD, Morelli AE. Regulation of immune responses by extracellular vesicles. Nat Rev Immunol. 2014;14:195-208.

6. Gunasekaran M, Sharma M, Hachem R, Bremner R, Smith MA, Mohanakumar T. Circulating exosomes with distinct properties during chronic lung allograft rejection. J Immunol. 2018;200:2535-41.
See Article page e129.

\section{Commentary: It's time for exosomes to get the limelight in lung transplant}

\author{
Michael K. Y. Hsin, FRCS, CTh, ${ }^{\mathrm{a}}$ and \\ Mingyao Liu, MD ${ }^{\mathrm{b}}$
}

Lung transplant (LTx) recipients have the worst outcomes among all those receiving solid organ transplants, with 50\% of recipients developing chronic lung allograft dysfunction (CLAD). ${ }^{1}$ Understanding the immunology of LTx is an important step toward improving these outcomes. In this issue of the Journal, Hwang and colleagues ${ }^{2}$ reviewed the potential role of exosome-based allorecognition pathways in LTx rejection, which seems to be a missing link between the innate and adaptive immunity and the development of CLAD.

The term exosome was first used by Johnstone and colleagues $^{3}$ in 1987 to describe sacs filled with smaller vesicles in maturing reticulocytes. Previously, exosomes had been regarded as a waste disposal mechanism. They are now understood to play important intercellular communication roles in normal physiology, such as reproduction and development, ${ }^{4}$ immune modulation, ${ }^{5}$ skin pigmentation, ${ }^{6}$ and modulation of host defenses against pathogens. ${ }^{7}$ In pathologic states, exosomes have been shown to be involved in neurologic diseases, ${ }^{8}$ cardiomyocyte hypertrophy, ${ }^{9}$ and cancer cell motility. ${ }^{10}$

In the review by Hwang and colleagues, ${ }^{2}$ important preclinical models of skin and heart transplant were cited to show alloreactive T-cell responses are initiated by donor

From the a Department of Cardiothoracic Surgery, Queen Mary Hospital, Hong Kong; and ${ }^{\mathrm{b}}$ Latner Thoracic Surgery Research Laboratories, Toronto General Hospital Research Institute, University Health Network, Toronto, Ontario, Canada.

Disclosures: The authors reported no conflicts of interest.

The Journal policy requires editors and reviewers to disclose conflicts of interest and to decline handling or reviewing manuscripts for which they may have a conflict of interest. The editors and reviewers of this article have no conflicts of interest.

Received for publication April 26, 2020; revisions received April 26, 2020; accepted for publication April 29, 2020; available ahead of print May 15, 2020.

Address for reprints: Michael K. Y. Hsin, FRCS, CTh, Department of Cardiothoracic Surgery, Queen Mary Hospital, Room 308, New Clinical Building, Hong Kong (E-mail: mkhsin@hotmail.com).

J Thorac Cardiovasc Surg 2021;161:e136-7

$0022-5223 / \$ 36.00$

Copyright (c) 2020 by The American Association for Thoracic Surgery

https://doi.org/10.1016/j.jtcvs.2020.04.155
Check for updates

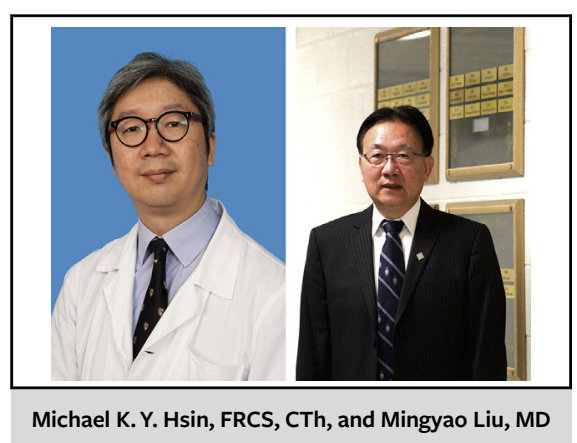

CENTRAL MESSAGE

Exosome-based allorecognition

pathways seem to be a missing

link between innate and adaptive

immunity and the development

of CLAD. Exosomes might be

potential biomarkers and targets

of therapy for CLAD.

exosomes, instead of passenger leucocytes, as previously accepted. ${ }^{11-13}$ New concepts, such as allo-exo-antigen, its production, and recognition pathways (direct, indirect, semidirect, and innate allo-exo-recognition), were introduced. These immunologic terms could be new to many thoracic and cardiovascular surgeons. However, understanding these new concepts could help us to develop new knowledge in the clinical LTx setting.

Exosomes have been implicated in the development of LTx rejection. The RNA profiles of exosomes extracted from bronchoalveolar lavage fluid from LTx recipients with acute rejection showed an inflammatory response, with signals of both innate and adaptive immune activation. ${ }^{14}$ The serum and bronchoalveolar lavage fluid of LTx recipients with acute rejection or bronchiolitis obliterans syndrome, the exosomes contained donor human leukocyte antigens HLA and self-antigens (SAgs). These were not seen in stable LTx recipients. ${ }^{15}$ Circulating exosomes 